\title{
METHODOLOGICAL FOUNDATIONS CONCEPTS OF NORMS AND INSTITUTIONS FOR
} INSTITUTIONAL ANALYSIS

\author{
Boris Kovalenko' \\ St. Petersburg National Research University of Information Technologies, Russia
}

\section{ABSTRACT}

Institutional analysis of the Russian economy becomes relevant in the process of transformation and development. Relevance of research institutions due to the fact that institutions have an impact on the national business model. The long process of institution building, the difference between their composition and properties in comparison with the economies of the European Union and the U.S., confirms the inevitability of self-development of each country. The author sees a problem in the fact that the development of a market economy in Russia, by the standards of industrialized countries, are inevitable: a long time, significant social costs and social consequences. As the research activities of Russian corporations and for the establishment of a modern economy the problem is not to create a market mechanism of the economy, and to build its institutional environment, which allows the market to function efficiently with acceptable social consequences. Investigation of the role of institutions in the prosperity and well-being of countries with market economies, led me to the need to separate the coordination and distribution functions of institutions. It is suggested that in the context of asymmetric information these functions determines the appearance and coordinating the distribution of effects. The first mechanism is to reduce the uncertainty of the market environment, the second - the mechanism of diversification of resources and the benefits of economic agents. The interaction of these mechanisms, in my opinion leads to lower costs of economic agents. Moreover, the degree of asymmetry of information, the level of costs and the role of institutions in regulating the interactions of agents are directly proportional. As a result, it was concluded that the institutions are the most important instrument of formation, development and management behaviors of economic agents.

\section{UDC \& KEYWORDS}

॥ B52 — INSTITUTE ॥ STEADY RATE ॥ RULES — REGULATIONS - INSTITUTIONAL ARRANGEMENTS - COORDINATING THE DISTRIBUTION FUNCTIONS OF INSTITUTIONS

\section{INTRODUCTION}

Study of institutional arrangements of the Russian economy is particularly relevant at the present stage of transformation of the domestic economy and the development of the economic system. Historical economic institutions significantly affect the formation of a national economic model. The long process of their formation, composition and specificity as compared with the peculiarities of other countries confirms the inevitability of the distinctive character of the economy of each country. The fact that the formation of a market economy requires long periods of improving the institutional system suggests that its becoming more difficult becomes the functioning of the market mechanism, and its institutional environment, which allows him to work effectively with acceptable social consequences.

' kovalenkob@mail.ru
Methodological basis of the conjugation notions of «normal» and «institution» in the institutional analysis

It is known that not all countries, even with extensive experience in the organization of the market economy and a significant arsenal of means of control can be attributed to a thriving and prosperous country.

We are aware that the institutional structure of the economy of a country is not absolutely constant. Her improvement, informed and thoughtful reconstruction, transformation and removal of individual elements - all these serves the immediate area of the most transformative activity, identifying one of the most important components of the process of economic reform. As evidenced by international and domestic experience, institutional change has high complexity, requires a thorough theoretical study and the considerable period of time. With such problems, met the Russian economy at the present stage of development.

The key concept used by numerous representatives of the analyzed current economic theory supports the notion of "institution", which meant the introduction of a departure from the separate consideration of the individual as an object of study and analysis. Despite the active development of institutional economic theory, both abroad and in our country, various researchers adhere to its own definition of this concept.

The analysis of the concept of "institution" in the statements of foreign and domestic authors suggest that most of the opinions converge in the fact that the concept of "institution" is correlated with the notions of "norms" and "rules." To clarify the concept of "institution" must first answer two basic questions: Do any public provision can be the basis of the Institute or, in other words, the institutionalized norm. For example, Grebennikov (1998) proposes to distinguish the concept of rules imposed or recommended by the individual and ethical standards, adherence to which is the result of choices made by the individual.

Both types of rules, no doubt, are important components of institutional norms in general, but did not disclose their contents completely. Are not reflexive and not related to ethical standards, many of which are given individual sets for himself, working from the inner motives and in conformity with the external factors. For example, the rule "under any circumstances to fulfill their obligations" is not one of ethics, but are not reflexive.

In our view, a significant difference between the operation of a facility (rules, norms) as an internal or external does not. Neither the degree of rigor, or the inevitability of sanctions for violation of the rules can not be used to distinguish between internal and external standards. Based on the foregoing, in this paper the norm we mean the rule, addressed to one or a group of agents, defining characteristics of the perception and use of information for decision-making, choice behavior and the formation of relationships in society. The rule may be due to tradition, custom, stereotype behavior or indications. The concept of 
agent introduced us to the research tools according to the tradition of institutional agent theory of Stiglits. By agent we mean the entity acting in the market and nonmarket interactions in the form of individual or organization.

Following the principle of binding the "norm-institution" of the existing positions of the definition of "institution", select the three options, which are presented in table 1.

The first is the individualized determination of the institutions as a relatively independent entity that is a stable institution refers to the norm.

The second system is characterized by the definition of institution as a set of role relations, or the traditions and routines (repetitive actions that ensure and oversee the smooth functioning of the organization).

The third qualifies as a dualistic definition, that is, the notion of "institution" includes the rate and mechanisms for controlling and supporting its implementation.

\begin{tabular}{|l|l|}
\hline Table 1: Approaches to the definition of "institution" \\
\hline Option & Content \\
\hline First & Steady rate \\
\hline Second & Complex traditions and routines \\
\hline Third & $\begin{array}{l}\text { The rate and mechanisms to support its } \\
\text { implementation }\end{array}$ \\
\hline Source: Author \\
\hline
\end{tabular}

Analyzing the concept of "institution", we felt it necessary, first of all, to answer the question: is there a need to include the presence of specific support mechanisms in the composition of the essential characteristics of the institute? An affirmative answer would mean that a particular rule (rule) is only Institute in conjunction with some other special kind of rules and regulations, as do supporting mechanisms - nothing more than how certain rules and regulations. But as soon as it is, these latter rules should also be equipped with appropriate mechanisms, etc.

It turns out that may be recognized by institutional mutually supportive standards. So we come to the definition of institution as a system support one another in a set of rules (the rules) (Kleiner. The formation of micro-economic institutions, 2004). In our opinion, the term "norm" in conjunction with the requirement of stability is valid, regardless of whether it is possible to identify specific mechanisms to support this standard. Consequently, such a definition to the heart of the concept of "institution". Therefore, the traditional definition of institution only as a set of social norms in conjunction with the mechanism of control over the activities of the subject and the impossibility of deviation from it is we do not complete.

We now clarify the notion of sustainability standards. It is not only the duration of its functioning and stability over time, although this condition is necessary. Most importantly, the rule should exist regardless of the current actions of one or a group of agents. Stability is normally attached to her property as rooted in social consciousness. Otherwise, this property is formulated as the institutionalization of the norm. Stable or institutionalized norm, as rightly observes Kleiner (2004), can be likened to a giant rock, which is not able to budge on their own or an agent or group of agents (Kleiner. The evolution of institutional systems, 2004). Only came together in a meaningful number, or by using special procedures, the agents may destroy or budge the stone. Thus, to institutionalize the rule should be stable with respect to any action as a single agent or group.

As for the system of definitions of the second direction, their use can be difficult because of problems with the establishment of an integrated system of border corresponding to the concept of the institution. Therefore, it is advisable to stay on the definitions of the first direction, without neglecting the advantages of the second and third lines. Having in mind a specific institute a system of rules and regulations, we allow for the designation of the Institute the use of key standards.

If the institution is a system of norms, legally, in our view, these rules structure. In other words, identify rules that represent the "core" institution that preserves stability under all conditions and rules are more flexible, dynamic, and playing the role of "protective layer" between the actions of agents and a relatively stable core. Based on these considerations, the system of rules is presented in table 2 .

Along with system performance standards, we consider that the rules are the product of multi-dimensional people. In this regard, the rules can be created in a centralized and a decentralized manner, a deliberate and spontaneous origin. Standards are different types, the variety is determined by the complex structure of the agents and the richness of their economic practices.

Analysis of different types of standards, their classification, in our view, contributes to the understanding of the importance of the role of traditions, customs and norms (rules) in the behavior of economic agents, which is a fundamentally new methodology of economic institutions in the theoretical analysis. This greatly expands the scope of the determinants that affect the economic behavior of agents. Given the nature of economic institutions in economic processes is well illustrated by the situation in Russia.

\begin{tabular}{|l|l|}
\hline \multicolumn{2}{|l|}{ Table 2: System components of institutions } \\
\hline Component & Content \\
\hline Basic rules & $\begin{array}{l}\text { Express the main points of the Institute and is its } \\
\text { "core" }\end{array}$ \\
\hline $\begin{array}{l}\text { Additional } \\
\text { standards }\end{array}$ & Form a "protective layer" of the Institute \\
\hline $\begin{array}{l}\text { Supporting } \\
\text { standards }\end{array}$ & $\begin{array}{l}\text { Determine the mechanisms for monitoring, control } \\
\text { and support compliance with the "core" of the } \\
\text { Institute }\end{array}$ \\
\hline Source: Author \\
\hline
\end{tabular}

The economic behavior of entrepreneurs, and for Russia it is a new, resurgent social group, as shown by even a simple observation, predicated not so much by new laws passed (centrally established, binding on the rules), and the emergence of new institutions (banks, stock exchanges, etc. ), but informal norms that arise in the process of living and economic activity. This characteristic is peculiar and traditional social groups such as labor collectives of large enterprises whose behavior is much more influenced by the prevailing economic traditions and behaviors.

It seems necessary to give some explanation of certain types and characteristics of norms. Thus, formal and informal rules differ in that first been documented, their creation, as a rule, is the deliberate character, and the creation process can be centralized or decentralized form, the second - the documentary form does not have, due to the fact that they exist in an implicit as an element of consciousness. The sources of informal norms can serve as a national and historical traditions, ideologies. If society is subjected to a purposeful ideological effect, these rules can be created intentionally. However, it is typical to natural (spontaneous) development of informal norms and presents the result of natural development of society. 
Following the formal or informal agent rules is either discrete or continuous. That is the choice in favor of the sanctioned behavior is realized each time the agent enters the appropriate conditions. In the latter case the choice of a meaningful comparison of the alternatives available. Following the norm is automatic and takes the form of habits. Gradually, the habit becomes a routine, then the agent should be the norm unconsciously.

Norms, as we have previously noted, suggest the existence of mechanisms and organizations that encourage agents to conduct. Thus, Groshev (2004) offer is meant by "a set of forms and mechanisms through which ensured the implementation of norms, the corresponding organizational institution". We believe that this organization is secondary to the standards that form the core content of the institute. Hence, the dependence of the forms of organization of the nature of the norm. For example, a system of informal rules can not be implemented legal organizations. It involves the use of informal mechanisms, such as obstruction of the subject agent, etc.

Thus, each institution is organizing a special system of controls and incentives, which is different content of these mechanisms, as well as their relationship. Specific organizational Institute does not operate in isolation. Agent is a complex combination of different processes. The agent involved in a large number of interactions, each of which is based on their behavior. Therefore, in practice the agent is dealing with a system of institutions (institutional actors).

For further analysis, it seems necessary to distinguish between the concept of "institution" and "organization". In the literature there are significant discrepancies in the use of these concepts. Some authors consider the organization as a special case of formal institutions. Others, consistently following the ideas of (North, 1990), believe that the relationship between organizations and institutions - such as between the parties to the game and the rules of the game, in other words, organizations are subjects of the institutions. In our opinion, the organization can be considered as subjects of institutional norms. But, in addition, each organization is inextricably linked to a range of general stable microsocial norms and rules relating only to a particular organization, membership, coordinate the activities of members, etc. Almost every organization has its own specific cultural and functional "mikroinstitutions", a complex which can be identified with the name of the organization.

Thus, on the one hand, an organization can act as a subject of institutional behavior (organizational Institute), and institutional interactions, on the other - to be the scene of the Interior and other institutions. In accordance with the above, we formulate a definition of "institution", which will be used in the future.

By institutions we mean a relatively stable with respect to changes in behavior or interests of individual actors (or groups), informal and formal rules (or system of rules) that govern the interaction of actors (or groups) through a special mechanism or organization. For the name of the institute can be used as a key norm, such as "institution of bankruptcy" and the key object, for example, "Institute for Public-Private Partnerships."

Similar to the classification standards, institutional theory, various classifications of institutions, the contents of which are generally consistent with the goals and objectives set forth by researchers in a specific period of time. However, there are the most common, most often used to analyze the classes of institutions.
Institutions, in their totality form two large groups - formal and informal. Informal institutions arise from the information transmitted through social mechanisms, and in most cases is that part of the heritage, which is called culture. Informal institutions have been crucial in this period of human history, when the relationship between human beings are not governed by formal laws. Informal institutions, acting as a constraint, and permeate all the modern economy. Originating as a means of coordinating sustainable forms of repetitive human interaction, informal constraints are formal rules of modification, behavioral norms, standards and binding (North, 1990).

In fact, the role of informal institutions does business ethics, research is devoted to a large number of scientific research (Weber, 1990). Economic Ethics raises the level of public ethics, therefore, the economic coordination of the market. If the existing ethical norms in a society allow economic entities in their actions based more on trust than on the possibility of sanctions, certain formal law, in such a society, the transaction will be more regular and complex. It is proved in Coleman (1994). Formal rules and restrictions arise on the basis of already existing informal rules and mechanisms for their implementation. In the structure of formal institutions stand out: the institutions of economic, political, and contracting institutions that govern technology contracts by applying the law.

Modern economics has paid much attention to the study not only the economic institutions that shape the behavior of economic agents and political institutions that define the hierarchical structure of power in society, how the decisionmaking and control. Evolution and function of formal political institutions is the subject of study of a large number of researchers who have chosen to analyze the institutional approach (Buchanan, 1997, Buchanan \&Tullock, 1997, Muller, 2002). Formal economic institutions in the scientific literature are considered most often in a context of property rights, because they "establish property rights, that is rights to use pencil and income from property, and the exclusion of others from using the property or resources" (North, 1990).

Institutions contracting conditions determine the agreement between buyer and supplier, which depend on three factors: price, warranty, asset specificity (Williamson, 1996). Institutes of contracting, along with property rights are the basic institutions of the institutional structure of any economic order, such as the economic system. For the effective functioning of the free market economy contracts is crucial. A departure from the principle of freedom of choice agent for the contract is the cause of complications of contracting procedures, which reduces the efficiency of exchange (Shumpeter, 1995).

\section{The main features of institutions}

Institutions are a very complex system, elements of which have differences in their internal content, and the nature of the interaction between them, as well as external socioeconomic objectives and processes. For example, institutions such as the "Institute of Corporate Governance" refers to the basic institutions of modern society, and the Institute "Annual Meeting of Shareholders of JSC" Lukoil "is a local enterprise, since belongs to the same organization. Some institutions, such as the "institution of stock values," is a more global systems that shape the activities of many international and national organizations, whose work involved the mass of agents. Other institutions, such as "project finance institution," as narrowly as possible, which may relate to the interests of a small number of subjects. There is absolutely unique institutions, and institutions are 
universal. However, in our opinion, there is no reason to exclude this or that rule of the number of institutions only because of the limited set of subjects to whom it is addressed.

It encourages the media to introduce the concept of the Institute as a set of entities or systems that can be covered or actually covered by this institution. The carrier may be nominal and the actual. In the first case, this means that the effect of this provision applies to the entire set of agents, and the second - a set of agents who are ready to really follow it.

In general, each institution can be characterized by the following attributes:

1. the type of agents that are intended to include this provision (citizens, government agencies, corporations, and subjects of the federation, etc.) This is the type of the nominal carrier Institute;

2. the set of agents of this type, which is intended, the rule (eg, citizens who have reached retirement age, the concrete plant, and all commercial organizations of the city, subjects of the federation, the North-West Federal District, etc.) This set is called the nominal or potential carrier of the institution;

3. the set of agents of this type, in fact complying with this provision (subject to the intermediate grades, characterizing the set of agents who adhere to this standard in a certain period of time under certain circumstances, etc.) This is the actual support of the Institute;

4. the scope of the decision-making area of activity or the relationship of agents regulated by this rule;

5. the time of occurrence, period, or the stability of the institute;

6. the degree of formalization of the Institute, its consolidation in the legal and regulatory framework;

7. the type of mechanisms to inform the affected data subjects about the institution of the norm;

8. the type of mechanisms of direct control over the observance of the rules.

The concept of media institution or of the rule itself can become the basis for the definition of the institute. For example, V.M. Bychenkov divides the set of social units into three categories: individuals, collective social formation with a fixed personal accessory, "super collective" social education with an indefinite personal staff. In his opinion, the term "institution" in its content and meaning is most suitable to describe it super collective social formations (Bychenkov, 1996).

By analyzing the logical line "individuals - groups", Bychenkov (1996) uses to characterize "super collective" entities, the term "abstract entity". In fact, here we are talking about using two-way communication "institution" - "media." This kind of definitions are equivalent bond "rate - the carrier of the norm."

Classification of institutions can be obtained from the classification of certain features. If the share holders of the Institute for an indefinite or a specified number of agents and institutions are divided into formal and informal, we arrive at the proposed Tambovtsev (1997) classification of institutions:

1. a formal structure for an indefinite group of participants;

2. formal structures for a specific group of participants;

3. the informal structure for an indefinite group of participants;

4. the informal structure for a particular group of participants.

Thus, the institution is characterized by a number of symptoms, and the difference of at least one of them needs to consider various relevant institutions.

Accordingly, the levels of the hierarchy of institutions can be divided into groups presented in table 3 .

Important to examine the institutional structure of society are represented as classification, based on a content division institutions. The most interesting and significant is the division of the classification of institutions of the "regulatory", that is, a priori existing regulatory or potentially possible action, and "constructive", which creates the possibility of some action. An example of a regulatory institution are, for example Standards for securities issuance and registration of the Prospectus and constructive - the institution of the loan.

\section{The functions of institutions}

How stable the formal and informal norms, institutions directly affect the behavior and performance of economic agents, limiting their choice of size and structure of resources, direct their activities in the predicted direction. Through the same mechanisms which institutions acquire and exercise their economic importance?

First of all, we believe that institutions limit access to resources and diversity of options for their use, there are constraints in the problems of economic decision-making. By limiting the possible modes of action and behavior, institutions, co-ordinate the behavior of economic agents find themselves in a situation described by the terms of the relevant application standards.

Indeed, the description of the institution acting in a certain situation, gives each of the economic agents who are in it, information about how to behave, or its counterparty. Accordingly, agents may form their own line of conduct, taking into account the expected actions of another party, which means that the emergence of coordination in their interactions.

\begin{tabular}{|l|l|l|}
\hline \multicolumn{2}{|l|}{ Table 3: Hierarchical levels of institutions } & The value of this level in the hierarchy \\
\hline Levels of hierarchy & The components of the levels & \\
\hline Baselines & Global & Shape the behavior of actors at the global economic and international organizations \\
\cline { 2 - 3 } & National & $\begin{array}{l}\text { Determine the dynamics and trends of socio-economic processes in the framework of } \\
\text { the national economy }\end{array}$ \\
\hline Mesa & Corporate & Extend their action in the corporate sector of the economic system \\
\cline { 2 - 3 } & Regional & Nature of the actions covered in the regional system \\
\hline Microeconomic & Firm & $\begin{array}{l}\text { Refer to the decision-making at the level of firms, educated an individual entrepreneur } \\
\text { or as a partnership }\end{array}$ \\
\hline Nanoeconomic & Individual & Impact on the socio-economic behavior of individual agents-individuals \\
\hline Source: Author &
\end{tabular}


The most important condition for such coordination, in our opinion, is the awareness of agents on the content of the institute, which governs the behavior of the agent in a given situation at any given time. If an agent knows how to behave in certain circumstances, and the other not, the coordination may be impaired, resulting in the interaction of the participants may incur additional costs. The cost is higher, the greater the asymmetry of information that is available to agents to make decisions. Under asymmetric information the implementation of institutions responsible for coordination of actions of economic agents and produces results in the appearance of focal effect. Its essence is to provide savings for the economic agents on the costs of the study and predict the behavior of other economic agents, they are facing in different situations.

Indeed, if the rules are strictly carried out, no need to spend a special effort to ensure that predict how partners will behave: the scope of their possible actions explicitly outlined the current institution. Thus, the focal effect of institutions is realized through the reduction of uncertainty of the environment in which economic agents operate.

Reducing the uncertainty of the environment provided by the existence of institutions to plan and implement long-term investments, seeking to create greater value. In addition, savings in the study and predict the behavior of contractors, can also be used for productive purposes, strengthening the coordination effect. In contrast, in an uncertain environment, in the absence of functioning institutions, economic agents do not only face lower expected benefit from the planned investment (which can obviously lead to a denial of their implementation), but are forced to spend money on a variety of precautions in carrying out economic activities. For example, for insurance transactions, or their individual components. Therefore, in our view, rightly assume that the focal mechanism of the effect is leveling the uncertainty of the market environment and reduce costs.

In our view, the effect of clearing institutions occurs and manifests itself as a positive influence on the economy, only if the institutions are consistent with each other on the prescribed lines of action of economic agents. In the event that different rules (rules) that match the conditions of their application, determine the divergent behaviors, the uncertainty of the environment for economic agents increases, if there is no standard set of institutions (rule), the ordering of the conflicting rules.

Therefore, the coordination effect, inherent in any single institution, when considering the totality of institutions may or may not occur if they are not coordinated.

Any institution, limiting the options for possible selection affects the distribution of resources, economic agents, performing a distribution function. Distributional consequences of the Institution may be for the agents is not straightforward. In addition to a variety of specific and any institution is characterized by some common, "standard" distribution effect. By limiting the number of possible modes of action, institutions or directly to switch resources to their authorized subset, or at least increase the cost of illegal methods of action, to include in their composition of the expected damage from the application of penalties (sanctions) against an infringer of the rules. Therefore, we believe the implementation of a valid picture of the distribution of the effect through the mechanism of the influence of institutions on diversification of resources, benefits and costs.
Thus, the functions of coordination and distribution of results in the economic importance of institutions in terms of information asymmetry determines the performance of these functions and the emergence of co-ordinating the distribution of effects. The first mechanism is the leveling of the uncertainty of the market environment, and the second a mechanism of diversification of resources and benefits of economic agents. The interaction of the identified mechanisms leading to lower costs of economic agents. Moreover, the degree of information asymmetry, the magnitude of the costs and the role of institutions in regulating the interactions of agents are directly proportional. As a result, we conclude: institutions have become an essential tool of formation, development and regulation of behavior of economic agents.

\section{Conclusion}

Thus, the study of the category of "normal" and "institution" is an institutional approach in terms of primary importance. Together, the institutions are multi-level system. The economic role of institutions is revealed through the analysis of the coordination and distribution functions. Under asymmetric information the implementation of these functions determines the occurrence and co-ordinating the distribution of effects. The first mechanism is the leveling of the uncertainty of the market environment, the second a mechanism of diversification of resources and benefits of economic agents. The interaction of these mechanisms leads to lower costs of economic agents. Moreover, the degree of information asymmetry, the magnitude of the costs and the role of institutions in regulating the interactions of agents are directly proportional. As a result, the legitimate conclusion that the institutions have become an important tool for the formation, development and regulation of behavior of economic agents.

\section{REFERENCES}

Grebennikov, V. (1998). Association on the subject passed. Economics of contemporary Russia, 1, 117-122.

Kleiner, G. (2004). The formation of micro-economic institutions. In Ac. D.S. Lvov (Ed..), Russia in the globalizing world: The political and economic essays, pp.558-610. Moscow: Science.

Kleiner, G. (2004). The Evolution of Institutional Systems. Moscow: Science.

Groshev, V. (2004). Institutsional Economy: Study Guide. St.Petersburg: StPSUEF Press.

North, D. (1990). Institutions, in stitutional change and economic performance. Cambridge: University Press.

Weber, M. (1990). The Protestant Ethic and the Spirit of Capitalism. Selected Works. Moscow: Progress.

Kozlowski, P. (1996). Ethics of capitalism. Evolution and Society. St.Petersburg: State University Press.

Sen, A. (1996). On ethics and economics. Moscow: Science.

Hayek, F. (1992). Fatal conceit. Errors of Socialism. Moscow: News. Rih, A. (1996). Economic Ethics. Moscow: Seeding.

Coleman, J. (1994). Foundations of Social Theory. Harvard: University Press.

Buchanan, J. (1997). Boundaries of freedom. Between anarchy and Leviathan. In J. Buchanan (Ed.), Nobel laureates in economics. Moscow: Alpha Taurus.

Buchanan, J. \&Tullock, G. (1997). Calculation of the agreement. Logical Foundations of Constitutional Democracy. Buchanan, J. Works. Moscow: Alpha Taurus.

Muller, D. (2002). Theory of public choice. In Grineueya, D., Bleaney, M. \& Stewart I. (Eds), Panorama economic thought in the late twentieth century (Vols.2, pp. 248-293). Trans. from English, 
In Avtonomov, V. \& Afontsev, S. (Eds). St.Petersburg: Higher School of Economics.

Furubothn, E. \&Richter, R. (2000). The Contribution of the New Institutional Economics. St.Petersburg: University Press.

North, D. (1990). Institutions, institutional change and economic performance. Cambridge: University Press.

Williamson, O. (1996). The Economic Institutions of Capitalism. St.Petersburg: Lenizdat Sev Press.

Schumpeter, J. (1995). Capitalism, Socialism and Democracy. Moscow: Economy.

Bychenkov, V. (1996). Institutions: super collective forms and impersonal forms of social subjectivity. Moscow: Russian Academy of Social Sciences.

Tambovtsev, V. (1997). Theoretical questions of institutional design. Problems of Economics, 3, pp. 82-94. 